\title{
Distribution and sources of linear alkyl benzenes (LABs) in surface sediments from Johor Bahru Coast and the Kim Kim River, Malaysia
}

\begin{abstract}
This study focuses on sewage pollution, which is one of the most important issues concerning Malaysians. The main location of this study is in Johor Bahru as it is one of the most populated areas in Malaysia. The distribution and sources of linear alkyl benzenes (LABs) were evaluated in surface sediments collected from Johor Bahru Coast and the Kim Kim River, Peninsular Malaysia. The samples were extracted, fractionated and analyzed using gas chromatography-mass spectrometry (GC-MS). This study found that LABs concentrations ranged from 87.6 to $188.7 \mathrm{ng} / \mathrm{g} \mathrm{dw}$ and 88.2 to $119.02 \mathrm{ng} / \mathrm{g} \mathrm{dw}$ in surface sediments from Johor Bahru Coast and the Kim Kim River, respectively. Johor Bahru Coast showed an increasing trend of LABs concentrations due to rapid industrialization and population growth. The ratio of internal to external isomers (I/E ratio) of LABs in sediment samples from Johor Bahru Coast ranged from 1.76 to 2.04 while the I/E ratios in sediments from the Kim Kim River ranged from 1.72 to 1.91. All I/E ratios at Johor Bahru Coast and the Kim Kim River stations indicate that the areas were receiving primary and secondary effluents.
\end{abstract}

Keyword: I/E ratio; Johor Bahru Coast; Kim Kim River; Linear alkyl benzenes; Malaysia; Sewage 